\title{
Yeraltı Maden İşletmeciliğinde Sağlık ve Güvenlik Sorunları
}

\author{
Gökhan AYDIN ${ }^{1}$, İzzet KARAKURT ${ }^{1}$ \\ ${ }^{1}$ Karadeniz Teknik Üniversitesi, Mühendislik Fakültesi, Maden Mühendisliği Bölümü, 61080, Trabzon
}

(Alınış / Received: 29.06.2020, Kabul / Accepted: 16.01.2021)

Anahtar Kelimeler
Yeraltı Madenciliği,
Sağlık,
Güvenlik,
Önlem

Anahtar Kelimeler

Sağlık,

Önlem

\begin{abstract}
Özet: Yeraltı maden ișletmeciliği kapsamında yürütülen faaliyetlere bağlı olarak sağlık ve güvenlikle ilgili çeşitli sorunlar yaşanabilmektedir. Zararlı gazlar, yangınlar, tozlar, sular, termal konfor, göçük, tasman, seyrelme, titreşim ve gürültü bu sorunlardan bazılarıdır. Üretim sürecinde daha çok meydana gelen bu sorunların nedenlerinin açı bir şekilde ortaya konulması ve gerekli önlemlerin alınması, iş sağlığı ve güvenliği açısından elzemdir. Bu çalışmada; ilgili sorunların nedenleri, etkileri ve çözümleri üzerine kapsamlı bir literatür taraması gerçekleştirilmiştir. Çalışma sonuçları, yeraltı maden işletmeciliği kapsamında yürütülen faaliyetlere bağlı olarak meydana gelen sorunların uygun yöntemler ile önlenerek, ilgili faaliyetlerin sağllk ve güvenlik tehlikesi oluşturmadan verimli bir şekilde sürdürülebileceğini göstermiştir.
\end{abstract}

\section{Health and Safety Problems in Underground Mining}

\section{Keywords}

Underground Mining,

Health,

Safety,

Precaution

\begin{abstract}
Various problems related to the health and safety may occur depending on the activities carried out within the scope of underground mining. Harmful gases, fires, dusts, waters, thermal comfort, caved area, subsidence, vibration and noise are some of these problems. It is essential in terms of occupational health and safety to clearly reveal the causes of these problems that occur more in the production process and to take the necessary precautions. In this study, a comprehensive literature review is carried out on the causes, effects and solutions of the related problems. The results of the study show that the problems that occur due to the activities carried out within the scope of underground mining operations, can be prevented with the appropriate methods and that the related activities can be carried out efficiently without creating a health and safety hazard.
\end{abstract}

\section{Giriş}

Madenler, ülkelerin bugünkü teknoloji ve refah düzeylerine ulaşmalarında önemli etkiye sahip olan ekonomik kaynaklarıdır. Yaşamı kolaylaştıran araç ve gereçlerin büyük bir çoğunluğunun üretiminde doğrudan veya dolaylı olarak maden ürünlerine ihtiyaç bulunmaktadır. İnşaat, metalürji ve seramik sektörü başta olmak üzere birçok endüstrinin (dolgu maddeleri, doğal boyalar, aşındırıcılar, değerli taşlar, elektronik, kimya vd.) en önemli girdisi madenlerdir [1]. Bunun yanında madencilik faaliyetleri, kaza ve ölüm risklerinin yüksek oranlarda olduğu bir faaliyettir. Yaşanan kazalar sonucunda maden işçileri yaralanmakta veya yaşamlarını yitirmekte ve telafisi mümkün olmayan acılar yaşanabilmektedir [2].

Madenler, açık ocak ve yer altı ocak işletmeciliği ile üretilmektedir. İş sağlığı ve güvenliği açısından her iki yöntem de benzer özelliklere sahip olmasına rağmen yeraltı maden işletmeciliğinde ortaya çıkan tehlikelerin, iş sağlığı ve güvenliği açısından ayrı bir önem arz ettiği söylenebilir [3]. Yeraltı maden işletmeciliği başlıca; etüt-planlama, hazırlık-üretim faaliyetleri, cevher-kömür hazırlama, pazarlama ve satış gibi faaliyetleri kapsamaktadır. İş sağlığı ve güvenliği açısından sorun teşkil eden durumlar genelde üretim sürecinde (hazırlık-üretim) ortaya çıkmaktadır. Üretim süreci; kazı, delme-patlatma, tahkimat, nakliyat, havalandırma gibi faaliyetleri içermektedir [4]. Bu faaliyetlerin gerçekleştirilmesi sırasında çeşitli sağlık ve güvenlik sorunları ortaya çıkmaktadır. Çalışanlar, bu sorunlarla sürekli veya belirli zaman dilimlerinde karşı karşıya kalmaktadır $[2,5]$.

Bu çalıșmada, yeraltı maden işletmeciliği kapsamında yürütülen faaliyetlere bağlı olarak meydana gelen önemli sağlık ve güvenlik sorunları detaylı bir şekilde ele alınmıştır. Yeraltı madenlerinde sağlık ve 
güvenliğe etki edebilecek çeşitli sorunlar tartışılmış ve bunların önlenmesine veya etkilerinin azaltılmasında etkili olabilecek önlemlerden bahsedilmiștir.

\section{Yeraltı Madenciliği ile İlgili Sorunlar}

\subsection{Zararlı gazlar}

Yeraltı madenciliğinde gerekli önlemlerin alınmaması durumunda çalışanlar, ocak havasının zararlı etkilerine maruz kalmakta ve ölümle sonuçlanabilecek durumlar meydana gelmektedir [68]. Madencilik faaliyetlerine bağlı olarak açığa çıkan gazları aşağıdaki gibi sınıflandırmak mümkündür [911]: i. Boğucu gazlar: Biyolojik olarak tesirsiz gazlardır [12]. Maden atmosferindeki oksijen oranını düşürerek boğucu etki meydana getirirler [13,14].

ii. Zehirli gazlar: Bünyesinde yüksek oranlarda zehirli gaz barındıran ve biyolojik etkisi bulunan gazlardır.

iii. Patlayıcı gazlar: İçerisinde yüksek oranlarda patlayıcı gaz bulunduran ve patlayıcı özellik gösteren gazlardır $[15,16]$.

Ocak atmosferinde sıklıkla bulunabilen tehlikeli gazların çeşitli özellikleri ve kaynakları, Tablo 1'de verilmiştir. Ayrıca bu gazların sağlık üzerindeki etkileri ve eşik değerleri ise Tablo 2'de sunulmuştur.

Tablo 1. Ocak atmosferinde bulunan tehlikeli gazların özellikleri ve potansiyel kaynakları [9-11]

\begin{tabular}{|c|c|}
\hline Gazın adı & Özellikler ve Potansiyel Kaynaklar \\
\hline $\begin{array}{l}\text { Karbondioksit } \\
\left(\mathrm{CO}_{2}\right)\end{array}$ & $\begin{array}{l}\text { Yoğunluğu } 1,6 \mathrm{~kg} / \mathrm{m}^{3} \text { olan bu gaz, havadan ağırdır ve asidik bir tadı vardır. Boğucu } \\
\text { özelliğe sahiptir ve yeraltında açıklıların tabanında birikir. Çalışanların solunumu, } \\
\text { karbon içeren herhangi bir maddenin yanması, ahşabın çürümesi, patlama ve } \\
\text { patlatmalar, sedimantasyon sırasındaki oluşumlar, volkanik olaylar, patarlı } \\
\text { motorlar, başlıca potansiyel } \mathrm{CO}_{2} \text { kaynakları arasındadır. }\end{array}$ \\
\hline $\operatorname{Azot}\left(\mathrm{N}_{2}\right)$ & $\begin{array}{l}\text { Yoğunluğu } 1,17 \mathrm{~kg} / \mathrm{m}^{3} \text { olan bu gaz atmosfer havasının \% } 78^{\prime} \text { ini oluşturur. Tüm canlı } \\
\text { dokularda bulunur ve boğucu bir gazdır. Organik maddelerin bozuşması, } \\
\text { kaya/kömür çatlaklarından yayılma ve patlatmalar potansiyel } \mathrm{N}_{2} \text { kaynaklarıdır. }\end{array}$ \\
\hline $\begin{array}{l}\text { Karbon monoksit } \\
\text { (CO) }\end{array}$ & $\begin{array}{l}\text { Yoğunluğu } 1,14 \mathrm{~kg} / \mathrm{m}^{3} \text { 'tür. Çok yüksek yayılma yeteneğine sahiptir. Zehirli bir } \\
\text { gazdır ve yeraltında açıklıkların tabanında birikir. Açık alevli olmayan yangınlar } \\
\text { başta olmak üzere diğer yangınlar, patlamalar ve patarlı motorlar potansiyel CO } \\
\text { kaynaklarıdır. }\end{array}$ \\
\hline $\begin{array}{l}\text { Hidrojen sülfür } \\
\left(\mathrm{H}_{2} \mathrm{~S}\right)\end{array}$ & $\begin{array}{l}\text { Yoğunluğu } 1,36 \mathrm{~kg} / \mathrm{m}^{3} \text { tür. En belirgin özelliği çürümüş yumurta gibi kokmasıdır. } \\
\text { Suda çok kolay çözünür, oldukça zehirli bir gazdır. Sülfürlü cevherlerin patlatılması, } \\
\text { su drenajı, organik maddelerin çürümesi, pirit-jips vb. minerallerin su ile ayrışması, } \\
\text { tam olarak gerçekleşmeyen patlayıcı madde ateşlemeleri ve kömürlü katmanların } \\
\text { yanması potansiyel } \mathrm{H}_{2} \mathrm{~S} \text { kaynaklarıdır. }\end{array}$ \\
\hline $\begin{array}{l}\text { Kükürt dioksit } \\
\left(\mathrm{SO}_{2}\right)\end{array}$ & $\begin{array}{l}\text { Yoğunluğu } 2,63 \mathrm{~kg} / \mathrm{m}^{3} \text { olan } \mathrm{SO}_{2} \text {, kükürtsü bir kokuya sahiptir. Bu nedenle gözü, } \\
\text { burnu ve boğazı tahriş eder. Zehirli bir gazdır. Yangınlar, ateşlemeler ve sülfürlü } \\
\text { cevherleri içeren kayaçların kazısı } \mathrm{SO}_{2} \text { gazının açığa çıkmasına yardımcı olur. }\end{array}$ \\
\hline Azot oksitler $\left(\mathrm{NO}_{\mathrm{x}}\right)$ & $\begin{array}{l}\text { Azot oksit, azot dioksit ve diğer türevlerdir (azot trioksit, azot tetraoksit ve nitröz } \\
\text { oksit). Zehirli gazlar olup azot patlamaları ve motorların egzoz çıkışları sonucu açığa } \\
\text { çıkarlar. }\end{array}$ \\
\hline Metan $\left(\mathrm{CH}_{4}\right)$ & $\begin{array}{l}\text { Yoğunluğu } 0,66 \mathrm{~kg} / \mathrm{m}^{3} \text { tür. Patlayıcı bir gaz olması ve havaya göre } 1,6 \mathrm{~kat} \text { daha hızlı } \\
\text { yayılması oldukça tehlike arz etmesine yol açar. Ocak havası ile \% } 5-16^{\prime} \text { lik } \\
\text { karışımlarında patlama meydana gelebilir. Kömür, kaya tuzu, potas, kükürt ve demir } \\
\text { madenleri potansiyel } \mathrm{CH}_{4} \text { kaynaklarıdır. }\end{array}$ \\
\hline
\end{tabular}

Tablo 2. Ocak atmosferinde bulunabilen gazların sağlığa etkileri [9-11]

\begin{tabular}{|c|c|c|c|}
\hline Gaz & $\begin{array}{c}\text { Etkilerinin başlangıç seviyesi-ilk sağlık } \\
\text { belirtileri }\end{array}$ & $\begin{array}{c}\text { Ölüm başlangıç } \\
\text { seviyesi }\end{array}$ & $\begin{array}{c}\text { Eşik } \\
\text { Değeri }\end{array}$ \\
\hline Oksijen & \% 15-Hızlı ve daha derin soluk alma & $\% 6$ & $\% 19$ \\
\hline Karbondioksit & \% 3-Nefes almak hafiften zorlaşır & $\% 25$ & $\% 0,5$ \\
\hline Karbon monoksit & $\%$ 0,01-Birkaç saat maruz kalınabilir & $\begin{array}{l}\geq \% 0.40 \text { ( } 1 \text { saatten az } \\
\text { sürede) }\end{array}$ & $\% 0,005$ \\
\hline Hidrojen sülfür & 50 ppm -Gözde ve boğazda tahriş & $\begin{array}{l}2000 \text { ppm (1 dakikadan } \\
\text { az sürede) }\end{array}$ & $20 \mathrm{ppm}$ \\
\hline Kükürt dioksit & $\begin{array}{l}20 \text { ppm -Öksürme; gözde, burunda ve } \\
\text { boğazda tahriș }\end{array}$ & $\begin{array}{l}400 \text { ppm (nefes almak } \\
\text { imkansız) }\end{array}$ & $7 \mathrm{ppm}$ \\
\hline Nitrik oksit & 25 ppm -Kısa sürede boğaz tahrişi ve öksürük & $200 \mathrm{ppm}$ & $5 \mathrm{ppm}$ \\
\hline
\end{tabular}


Gazlarla ilgili bir diğer problemde yeraltı kömür madenlerinde gözlenen ani metan ve kömür püskürmeleridir. Üretim çalışmaları ile bozulan basınç dengesinden dolayı kömür damarlarında (gözenek ve çatlaklarında) yer alan metan gazının kısa sürede sürüklediği malzeme (kömür+gaz karışımı) ile birlikte ayak açıklığını doldurabilmektedir [17]. Bu olay ani metan ve kömür püskürmesi olarak isimlendirilmektedir. Ani metan ve kömür püskürmeleri genellikle jeolojik deformasyona uğramıș ve aynı zamanda yüksek miktarda gaz içeren damarlarda ortaya çıkmaktadır. Olayın gerçekleşmesi için, kömür damarındaki gaz miktarının belirli değerlerde olması gerekmektedir $[8,18]$. Genel olarak, 8 m³/t'dan (kuru-külsüz kömür) daha büyük bir gaz içeriğine sahip kömür damarlarında, ani metan ve kömür püskürmesi gerçekleşebilmektedir (diğer koşulların da sağlanması şartıyla). Ani metan ve kömür püskürmesinde rol oynayan bir diğer faktör ise kömürün rankıdır. Rankı yüksek kömürler daha fazla metan gazı adsorplayabilmekte ve daha gevrek bir yapı göstermektedirler. Bu gevrek yapı nedeniyle kömür üzerindeki ikincil gerilmelerin etkisiyle kömürde yeni süreksizlikler meydana gelebilmektedir. Bunun sonucunda ise gazın desorpsiyon hızı artmakta ve damarın ani metan ve kömür püskürme eğilimi artmaktadır $[19,20]$.

\subsection{Ocak yangınları}

Yeraltında meydana gelen yangınlar, işçilerin güvenliği/sağlığını ve maden işletmesinin ekonomikliğini etkileyebilmektedir. Yeraltı koşullarında yangın çıkabilmesi için yakıt, oksijen ve ısının bir arada bulunması gerekmektedir. Çalışanların etkin bir şekilde solunum yapabilmeleri, ekipmanların çalışabilmesi ve çalışmalar sonucunda açığa çıkan gazların seyreltilmesi için havalandırma sistemleriyle yeraltına temiz hava gönderilmektedir. Temiz hava \% 21 civarında oksijen içermektedir. Dolayısıyla yeraltı atmosferinde yangının meydana gelmesi için gerekli oksijen sürekli bulunmaktadır $[21,22]$. Başlıca ısı kaynakları ise makineler, elektrik devreleri, kaynak yapımı ve diğer (sürtünme, kıvılcım ve alev oluşturan) aletlerdir. Ocak içerisinde bulunan yanıcı gazlar ve yanabilir nitelikteki katı/sıvılar bu kaynaklarla yanabilir. Bunun yanında, kömür madenlerinde uygun çevresel koşullarda kömür oksidasyona uğrayabilmektedir. Oksidasyon sonucunda meydana gelen isının ortamdan uzaklaştırılamaması sonucunda sıcaklık giderek artmaktadır [23,24]. Artan sicaklık (ortamda yeterli oksijen varsa) oksidasyon hızını ve kömürün sıcaklığını arttırmaktadır. Sıcaklığın, kömürün tutuşma sıcaklığına (kritik sıcaklık) ulaşması sonucunda ise kömür yanmaktadır. Bu olay kömürün kendiliğinden yanması olarak tanımlanmaktadır [25]. Kendiliğinden yanmayı etkileyen faktörler aşağıdaki gibi özetlenebilir [26,27]: i. Kömür özellikleri: Rank arttıkça kömürün oksijen adsorplayabilme yeteneği düşmekte ve kendiliğinden yanma eğilimi azalmaktadır. Kömürün nem içeriğinin artmasıyla oksidasyon hızı artmaktadır. Bu sebepten nemli kömürler genelde oksidasyona daha yatkındırlar. Kömürün mineral madde içeriği artmasıyla ise azalan karbon miktarına bağlı olarak kendiliğinden yanma riski azalmaktadır. Ayrıca, kömürün tane boyutu azaldıkça (havanın temas edeceği yüzey alanı artar) kendiliğinden yanma kolaylaşır. Bunun yanında, kömür içeriğindeki pirit nemli ortamlarda oksitlenebilmektedir. Oksidasyon sonucu açı̆̆a çıkan ısı kömürün sıcaklığını arttırmaktadır. Ayrıca, oksitlenme sonucunda pirit şişmekte ve kömür içerisinde çatlaklar-kırıklar meydana getirmektedir. Bu etkiler sonucunda ise kendiliğinden yanma riski yükselmektedir.

ii. Ocak havası: Havadaki nemin kısmi basıncı kömür neminin kısmi basıncından yüksek ise kömür havadan nem almaktadır. Yoğunlaşmayla birlikte açığa çıkan ısı ise oksitlenmeyi hızlandırmaktadır. Sıcaklık yükselmesi sonucunda oksidasyon hızı artmaktadır (tersi durumda ise kömür soğumakta ve oksitlenme yavaşlamaktadır).

iii. Üretimle alakalı durumlar: Dönümlü ve dolgulu çalışma yöntemlerinde göçük sahasına hava kaçakları engellendiğinden bu bölgelerde yer alan kömürlerin hava ile teması engellenecektir. Bunun sonucu olarak da kendiliğinden yanma ihtimali ortadan kalkacaktır. Ek olarak, ayak ilerleme hızının azalması/durmasıyla göçük bölgesine geçen hava kömürle uzun süre etkileşimde bulunarak kendiliğinden yanmayı başlatabilecektir. Bunun yanında, topuklu yöntemlerde, topuklarda oluşan çatlaklar kömürün kendiliğinden yanmasına zemin hazırlayabilmektedir.

Ocak yangınlarının yeraltında çalışanlar ve iş yeri güvenliğine etkileri aşağıdaki gibi özetlenebilir;

i. Yanma ürünü olarak açı̆̆a çıkan $\mathrm{CO}$ veya $\mathrm{CO}_{2}$ gazları ölümcül sonuçlar doğurabilir. Yanma sonucunda ocak atmosferindeki konsantrasyonu azalan oksijen solunum sorunları oluşturur. Yanma ürünü olarak oluşan duman görüşü engeller ve yangınla mücadeleyi zorlaştırır. Duman ayrıca içerisinde bulundurduğu gazlar nedeniyle sağlığa zarar verir.

ii. Yanma ürünü olarak açığa çıkan kirleticiler havalandırma sistemleri tarafından sağlanan hava akımıyla ocağın diğer bölgelerine taşınabilir. $\mathrm{Bu}$ durumda daha fazla çalışan yangının zararlı etkilerinden etkilenir.

iii. Yangınlar metan patlamalarını tetikler. Ayrıca, kendiliğinden yanma nedeniyle can kayıpları ve büyük rezervlerin terk edilmesi söz konusu olabilir [28]. 


\subsection{Termal konfor}

Termal konfor, üretimde verimliliği etkileyen önemli faktörlerdendir ve başlıca sıcaklık, nem ve hava akımının kontrolündedir. Termal konfordaki olumsuzluklar, verimlilikte düşüşe, dikkatsizliğe veya konsantrasyon bozukluğuna neden olur [29]. Bunların sonucunda iş kazaları, meslek hastalıkları ve yaralanmalar meydana gelebilir. Termal konforu etkileyen faktörler aşağıdaki gibidir [30,31]:

i. Ocak havasının sıcaklığı: Çalışanlar ve ocak havası arasındaki ısı taşınımı, vücut yüzey sıcaklığı ile ocak hava sıcaklığı dengeleninceye kadar devam eder. Denge durumundaki vücut yüzey sıcaklığı çalışanın ısıl açıdan konforunu gösterir. Ocak atmosferinde $19-20,5 \quad{ }^{\circ} C^{\prime}$ den uzaklaşıldıkça termal konfor azalmaktadır. Termal konfordaki azalmanın sonucu olarak çalışmalar daha uzun sürmekte ve çalışanlar dinlenmek amacıyla sık sık mola vermektedir.

ii. Nem: Ocak havasının sıcaklığının yüksek olması durumunda bağıl nem (\%80-100) bunalmaya neden olarak çalışma verimini düşürür. Ocak havası sıcaklığının düşük olması durumunda ise yüksek bağıl nem, üşüme ve ürperme hissine sebebiyet verir. Ocak atmosferinde bağıl nemin \% 30-80 aralığında olması sağlanmalıdır.

iii. Kişisel faktörler: Metabolik hız ve giysi yalıtımı da termal konforu etkileyen insan kaynaklı faktörlerdir [32,33].

Yeraltında yürütülen çalışmalarda, vücudun ocak atmosferine saldığı ısı ile metabolik ısının eşit olması durumunda ısı dengesi sağlanır. Dengenin sağlanamaması durumunda ise aşağıdaki durumlarla karşılaşılır:

i. Metabolik üretilen ısı atmosfere salınandan az ise kalp atışı hızlanır, kılcal kan damarları daralır ve istemsiz kas hareketleri başlar. Fazla ısı kaybından dolayı vücut ısısı düşer. ii. Metabolik üretilen ısı atmosfere salınandan fazla ise dinlenme ihtiyacı artar, kalp atışı hızlanır, terleme artar, dolaşım düzensizliklerirahatsızlık hissi oluşur ve vücut ısı almaya başlar [10,30].

Öte yandan, düşük ve yüksek sıcaklığın insan vücuduna etkileri Tablo 3'te verilmektedir.

\subsection{Toz sorunu}

Toz; cisimlerin mekanik etkiler sonucu parçalanmaları, kırılmaları ve ezilmeleri esnasında oluşan ve cisimlerin özelliklerini taşıyan çapı $1 \mathrm{~mm}$ 'den küçük, hava içinde asılı kalabilen veya zamanla çökelen parçacıklardır. Madencilik faaliyetlerinde tozlar kırma, öğütme, delme, patlatma, kazı vb. faaliyetler sonucunda meydana gelmektedir [34]. Toz, sağlıkla ilgili problemlere (akciğer hastalıkları) yol açabilir ve görüş mesafesini azaltır $[35,36]$. Ayrıca, makinelerin çalışma performansını etkiler ve patlayıcı özellik gösterebilir (kömür tozu). Bazı tozların izin verilen sınır değerleri Tablo 4'te sunulmaktadır.

Diğer tozlarla kıyaslandığında kömür tozu patlayıcı özellik de gösterdiğinden ayrı bir öneme sahiptir. Kömür tozu uygun koşullarda tutuşabilmekte ve havada bulunması halinde büyük patlamalara neden olabilmektedir. Toz patlamasının oluşabilmesi için havada askıya geçmiş bir toz bulutunun ateşleyici bir kaynakla teması gerekmektedir. Toz bulutu, tozun bir darbe etkisiyle ocak havasına karışmasıyla oluşur. Bu açıdan özellikle tavan, taban ve yan duvarlarda birikmiş olan tozlar böyle bir oluşuma zemin hazırlayabileceği için tehlike arz etmektedir [37]. Metan gazını patlatabilecek kaynaklar toz bulutunu da patlatabilmektedir. Yeraltı madenciliğinde, hem toz bulutu yaratabilecek hem de bu birikimi ateşleyebilecek iki ana kaynak bulunmaktadır $[39,40]$.

Tablo 3. Düşük ve yüksek sıcaklığın insan vücuduna etkileri [38]

\begin{tabular}{lll}
\hline Sıcaklık $\left({ }^{\circ} \mathbf{C}\right)$ & Tanım & \multicolumn{1}{c}{ Etki } \\
\hline$-10 /-25$ & Çok soğuk & Kuru ciltte çatlama ve soğuk riski (5 saat içinde) \\
\hline$-26 /-45$ & Aşırı soğuk & Vücudun açı yüzeylerinde donma riski (1 dk. içinde) \\
\hline$-46 /-59$ & Tehlikeli soğuk & Vücudun açık yüzeylerinde donma riski (30 sn içinde) \\
\hline$<-60$ & Tehlikeli soğuk & Vücudun açı yüzeylerinde donma riski (30 sn'den kısa) \\
\hline$+27 /+32$ & Sıcak & Halsizlik, sinirlilik, dolaşı̇m/solunumda sorun \\
\hline$+33 /+41$ & Çok sıcak & Isı çarpması, Isı krampları ve ısı yorgunlukları \\
\hline$+42 /+54$ & Tehlikeli sıcak & Güneş çarpması, lsı krampları veya isı bitkinliği \\
\hline$>+55$ & Tehlikeli sıcak & Isı veya güneş çarpması \\
\hline
\end{tabular}

Bunlar aşağıdaki gibi açılanabilir.

i. Metan patlaması: Metan patlamasıyla oluşan sıcak gazların genleşmesi sonucu hava şoku meydana gelmektedir. Hava şokuyla birlikte çökelmiş durumdaki toz havalanarak toz bulutu oluşturmaktadır. Hali hazırda yanan metan gazı ise bu bulutu ateşleyebilmektedir.

ii. Patlayıcı maddelerle yapılan ateşlemeler: Patlatma sonrası meydana gelen hava şoku toz bulutu oluşturabilmektedir. Kullanılan patlayıcı maddenin yeterince güvenli olmaması 
durumunda ise patlama alevi bu toz bulutunu ateşleyebilmektedir.

Her iki durumda da ateșlenen ilk toz bulutunun yanmasıyla oluşan yüksek sıcaklıktaki gazlar, genleşerek hemen yakınında yeni bir toz bulutunun oluşmasına yol açacaktır. $\mathrm{Bu}$ olayın süreklilik kazanmasıyla toz patlaması meydana gelmektedir. Kömür tozu patlamalarına etki eden faktörler ise aşağıdaki gibidir [4,42,43].

i. Toz içeriği: Uçucu madde içeriğinin artması tutuşmayı kolaylaştırır. Tozun higroskopik nem ve kül içeriği kömür tozunun yanmaz malzeme içeriğini oluşturmaktadır. $\mathrm{Bu}$ bileşenler, radyasyon yoluyla yayılan ısıyı yutar ve kömür tozu taneciklerine barikat uygulayarak patlamaların gelişmesini yavaşlatabilir.

ii. Toz miktarı ve boyutu: Yeraltı açıklıklarında çökmüş toz (\%25-30 uçucu madde içeren ince toz) miktarı $100-120 \mathrm{gr} / \mathrm{m}^{3}$ ve $300-400 \mathrm{gr} / \mathrm{m}^{3}$ olan ocaklar sırasıyla tehlikeli ve yüksek derecede tehlikeli olarak değerlendirilebilir. Patlamalarda yer alan tozlar 0,75-1 mm'den daha küçük boyutlardadır. Genel olarak tane boyutu azaldıkça (10 mikrona kadar) tozun patlayabilirliği artmaktadır.

iii. Tozun serbest nem içeriği: Nem, tozları bir arada tutarak serbest kalmasını engellemektedir. Yeterli miktarda bulunması durumunda kömür tozunun patlamasının da önüne geçebilir. Ayrıca patlama sonrası oluşan alevin sıcaklığının düşmesine de katkıda bulunur.

iv. Metan ve ateşleme kaynağı: Metan patlamasıyla oluşan hava şokuyla toz bulutu meydana gelmekte ve yanan metan gazı tarafından ateşlenmektedir. Güçlü ateşleyiciler zayıflarına göre kömür tozunu daha kolay patlatabilmektedir.

Tablo 4. Bazı tozların izin verilen sınır değerleri [41]

\begin{tabular}{|c|c|c|}
\hline \multicolumn{2}{|l|}{ Kayaç-mineral } & Sinır değer \\
\hline \multirow{2}{*}{ Silika (kristal yapıda) } & Kuvars (solunabilir) & $\left(10 \mathrm{~g} / \mathrm{m}^{3}\right) /\left(\% \mathrm{SiO}_{2}+2\right)$ \\
\hline & Kuvars (toplam) & $\left(30 \mathrm{mg} / \mathrm{m}^{3}\right) /\left(\% \mathrm{SiO}_{2}+2\right)$ \\
\hline Mineral & $\begin{array}{l}\text { Amorf yapıda (doğal diatomalı toprak içeren ), } \\
\text { silikatlar (\%1'den az kristal silika içeren), mika, talk } \\
\text { (asbest içermeyen, asbest içeren) sabuntaşı, portland } \\
\text { çimentosu, grafit (doğal) }\end{array}$ & $\left(80 \mathrm{mg} / \mathrm{m}^{3}\right) /\left(\% \mathrm{SiO}_{2}+2\right)$ \\
\hline \multirow{2}{*}{ Kömür tozu } & $\% 5$ ve daha az $\mathrm{SiO}_{2}$ içeren solunabilir toz & $2,4 \mathrm{mg} / \mathrm{m}^{3}$ \\
\hline & $\% 5$ 'ten fazla $\mathrm{SiO}_{2}$ içeren solunabilir toz & $\left(10 \mathrm{mg} / \mathrm{m}^{3}\right) /\left(\% \mathrm{SiO}_{2}+2\right)$ \\
\hline \multirow{2}{*}{ İnert veya istenmeyen toz } & Solunabilir kısım & $5 \mathrm{mg} / \mathrm{m}^{3}$ \\
\hline & Toplam toz & $15 \mathrm{mg} / \mathrm{m}^{3}$ \\
\hline
\end{tabular}

\subsection{Tasman}

Yeraltı madenciliğinin uygulandığı bölgelerde, üretim faaliyetleri sonucunda olușturulan boșlukların kontrolü için bazı seçenekler mevcuttur. Bunlar; topuklu üretim yöntemlerinin uygulanmasiyla tavanın desteklenmesi, üretim boşluklarının doldurulması ve üst bölgedeki katmaların göçertilmesidir [44,45]. Göçertmeli yöntemin uygulandığı madencilik bölgelerinde, deformasyon etkisi yeryüzüne kadar ulaşabilmekte ve yüzeyde geniş çaplı hasarlar meydana gelmektedir. Bu durum "tasman" olarak isimlendirilmektedir [46]. Tasman, madencilik faaliyetlerinin etki alanı içerisinde olan yollara ve yerüstü/yeraltı tesislerine önemli hasarlar verebilmektedir. Bunun yanında, yüzey morfolojisinin değişmesine, yeraltı/yerüstü su kaynaklarının ve enerji nakil hatları vb. mühendislik yapılarının etkilenmesine yol açmaktadır. Tasmanın etki alanı ve deformasyon etkisi yatağın geometrisi/boyutları, üretimin yeryüzünden derinliği ve katmanların (üretim ve üzerindeki) mekanikpetrografik özelliklerine bağlı olarak değişmektedir [47].

\subsection{Yeraltı suyu}

Yeraltı madenciliğinde yürütülen faaliyetlere bağlı olarak açığa çıkan su $20 \mathrm{~m}^{3} /$ ton'a kadar ulaşabilmektedir [48]. $\mathrm{Su}$ sorunları etkileri bakımından dolaysız ve dolaylı olmak üzere iki gruba ayrılabilir [49]. Dolaysız etkiler: Diğer tüm koşulların aynı olması durumunda dahi sulu ortamlarda yürütülen yeraltı madenciliği kuru ortamlarda yürütülenlerden daha maliyetlidir. Suyun miktarı, niteliği, kayacın cinsi vb. faktörler maliyet üzerinde rol oynamaktadır. Ani su baskınlarının meydana gelmesiyle faaliyetler durmaktadır. Ayrıca, baskının bir sonucu olarak can ve mal kayıları yaşanabilmektedir. Bunun yanında, bilindiği gibi yeraltı suyu asidik özelliktedir ve bu nedenle içerisinde çözünmüş kalsit içerir [50]. Yeraltı madencilik faaliyetleri sonucunda çalışma ortamındaki basınç dengesi bozulmakta ve kalsit çökelmektedir. Bunun bir sonucu olarak ortama karbondioksit salınımı meydana gelmekte ve drenaj sistemlerinde çökelen kalsitin yol açtığı tıkanmalar oluşmaktadır. Dolaylı Etkiler: Soğuk (çalışma ortamındaki su donar) ve sıcak (ocak havasında aşırı ısınma ve nemlenme) bölgelerde yürütülen madencilik faaliyetlerinde çalışanların ve 
ekipmanların performansı düşmektedir. Ayrıca, suda çözülmüş zararlı gazlar yeraltı suları ile taşınabilir [4,51]. Patlayıcı madde sarfiyatı, yükleme, tașıma ve zenginleştirme maliyetleri artan yeraltı suyu miktarının bir sonucu olarak yükselir. Ek olarak, ocak içinden su boşalmasına bağlı olarak çevre tabakalardan da çalışma alanına su aktarımı olabilir. Bu durum tasmana sebep olabilir.

\subsection{Göçük}

Yeraltında açılan boşlukların çevresinde yer alan tabakaların çeşitli nedenlerden ötürü tutulamayarak çökmesi veya kayması olayıdır. Başlıca nedenlerini aşağıdaki gibi özetlemek mümkündür [52].

i. Çevresel ve jeolojik nedenler: Yeraltı suları ve yüksek nem, yüksek basınçlar, kaya patlaması, jeolojik süreksizlikler

ii. Mühendislik hataları: Hatalı patlatma, üretim hataları (üretim açıklıklarının boyutlarının fazla olması, tavandaki çatlak/kesiklere dikkat edilmemesi, tahkimatı tamamlanmayan bölgelerde üretime devam edilmesi vb.), tahkimat hataları (yanlış tahkimat malzemesinin seçilmemesi, tahkimatın hasar görmesi/sağlam olmaması, tahkimat yetersizliği/eksikliği vb.)

iii. Yönetimsel hatalar: Denetim hatası, hatalı/yetersiz ekipman yetersiz eğitim, uygun olmayan çalışma koşulları

iv. Çalışan hataları: Kaza yatkınlığı, tecrübesizlik, fiziksel özelliklerinin yeraltında çalışmaya uygun olmaması, konsantrasyon ve motivasyon eksikliği, hatalı veya tehlikeli bir durumu fark edip önlem almama vb.

\subsection{Diğer}

Titreşim ve gürültü de yeraltı madenciliği açısından sorun teşkil edebilen diğer unsurlardır. Bu unsurların çevresel etkilerinin yanı sıra çalışanlar üzerinde de olumsuz etkileri bulunmaktadır $[53,54]$. Uzun süre titreşim yapan cihazları kullanan çalışanlarda davranış ve görme bozuklukları, osteoporoz (kemik erimesi), ağrılar (daha çok el, bilek ve omuzlarda), dolaşım sistemi ve bağlı olarak beslenme bozuklukları meydana gelebilir $[55,56]$. Kişisel faktörler, maruziyet süresi ve şiddeti belirtilen hastalıkların ortaya çıkmasında önemli rol oynar $[57,58]$. Gürültü ise yorgunluğun artması, konsantre olma yeteneğinin azalması, kulakta hastalıkların meydana gelmesi ve ruhsal bozukluklar gözlenmesi gibi çeşitli etkilere yol açmaktadır. Titreşimgürültüye maruziyet nedeni ile ortaya çlkabilecek hasarın derecesi maruz kalan çalışanın hassasiyeti, titreşim-gürültünün hasar sınırını ne kadar geçtiği, maruziyet süresinin uzunluğu ve titreşim-gürültünün sürekliliği gibi faktörlere bağlıdır.

\section{Sorunlarla Mücadele}

\subsection{Zararlı gazlarla mücadele}

Gaz konsantrasyonlarının takibi için gaz izleme ve erken uyarı sistemleri kullanılmalıdır. Gazların ölçümünde kullanılan sensörler, sabit ve taşınabilir sensörler olarak ikiye ayrılmaktadır [59]. Sabit sensörler, taşınabilir sensörlerden farklı olarak risk taşıyan kritik noktalara yerleştirilir [60]. Yeraltı maden işletmelerinde karşılaşılan gazların tespitinde kullanılan sensörler Tablo 5'te sunulmaktadır. Bu sensörler, çalıșma prensiplerine göre Tablo 6'da sınıflandırılmaktadır. Tüm noktalarda bulunan sensörler, yeryüzündeki ana izleme merkezinden takip edilmektedir. Elektrikli ekipmanların tümü bu merkezden kontrol edilebilir. Herhangi bir uyarı durumunda tehlikenin arttığı bölgelerdeki tüm makineler durdurulabilir ve bölgenin elektriğini kesilebilir. Otomatik olarak havalandırma sistemleri devreye alınabilir ve ilgili bölgeye sağlanan hava miktarı ayarlanabilir. İhtiyaç halinde havalandırma sistemlerinin durdurulması da mümkündür $[2,60]$.

Gaz konsantrasyonun kontrol altına alınabilmesi için etkin bir havalandırma planı uygulanmalıdır. Kontrollü patlatma teknikleri kullanılmalı ve suda çözülebilir gazların $\left(\mathrm{SO}_{2}, \mathrm{H}_{2} \mathrm{~S}\right.$ ya da $\mathrm{NO}_{2}$ gibi) açı̆̆a çıktığı patlatmalarda hava-su püskürtülmesi ile gazların emilmesi sağlanmalıdır. Akülerin şarj edilmeleri sırasında açığa çıkan hidrojen gazlarının kontrolü için şarj istasyonu izole edilmeli ve havası ayrı bir hava akımı ile seyreltilmelidir. Motorların bakım ve ayarları düzenli olarak yapılmalı ve açık alevli yangınlar önlenmelidir.

Metan gazı patlama ve püskürme özelliği taşımaktadır. Bu bakımdan etkin bir şekilde takip ve kontrol edilmelidir [61]. Metan patlamasının önlenmesi için metan gazının ortamdan uzaklaştırılması gerekmektedir. Bunun için mevcut seçenekler aşağıda özetlenmektedir $[62,63]$.

i. Metan gazının birikmesinin önlenmesi: Etkin bir havalandırma planı yapılmalıdır. Havalandırma, metan konsantrasyonu \%1'in altında tutacak şekilde tasarımlandırılmalıdır. Doğal havalandırma yerine mekanik havalandırma uygulanmalı ve metan drenajı ihmal edilmemelidir.

ii. Biriken metanın alev almasının engellenmesi: Yeraltında yapılan çalışmalarla metan seviyesi kontrol altında tutuluyor olsa da istenmeyen durumlardan ve önüne geçilemeyen sebeplerle metan emisyonu meydana gelebilir. Bu durum karşısında metan patlamasının önüne geçmek için ortamda biriken metanın patlamasına sebep olabilecek ateşleyiciler (açık alev kaynakları, elektrik tesisatı, aydınlatma ekipmanları, patlatmalar vd.) kontrol altına alınmalıdır [64]. 
Tablo 5. Yeraltı maden işletmelerinde kullanılan gaz tespit sensörleri [60]

\begin{tabular}{ll}
\hline Gaz & \multicolumn{1}{c}{ Tespit yöntemi } \\
\hline Metan & Katalitik oksidasyon, isl iletkenlik, optik, akustik \\
\hline Oksijen & Elektrokimyasal, paramanyetik \\
\hline Karbonmonoksit & Elektrokimyasal, katalitik oksidasyon, yarriletken, kızı̈ötesi \\
\hline Karbondioksit & Optik, kızlötesi \\
\hline Kükürtdioksit & Elektrokimyasal, kızılötesi \\
\hline NOx & Elektrokimyasal \\
\hline Hidrojen sülfür & Elektrokimyasal, yarı iletken \\
\hline Hidrojen & Katalitik oksidasyon \\
\hline
\end{tabular}

Tablo 6. Çalışma prensiplerine göre sensörlerin sınıflandırılması [60]

\begin{tabular}{lll}
\hline Sensör tipi & Fiziksel değişim & Sinyal kaynağı \\
\hline Katalitik (pelistör) & Sıcaklı ya da ısı & Wheatstone köprüsü \\
\hline Optik (kızılötesi, & Absorbans lüminesans, & Gaz ya da bazı indikatörlerle reaksiyon, kimyasal reaksiyon \\
lazer, fiber optik) & kırılma indisi, saçılım & sonucu yayllım, örnekteki belirli boyuttaki taneler \\
\hline Yarı iletken & Elektriksel & Çalışma fonksiyonundaki değişimler \\
\hline Elektrokimyasal & Voltametrik & Elektrotlar arasındaki akımın değişimi
\end{tabular}

Metan ve kömür püskürmesine karşı alınabilecek önlemler ise aşağıdaki gibidir [65-67].

i. Kazı arınında rahatlatma sondajlarının açılması: Sondajlarla damar içerisinde ikincil çatlaklar oluşturulmaktadır. Böylelikle gaz, kazı boşluğuna daha kolay ulaşabilmektedir. Sondaj çapı genelde 65-140 mm arasındadır. Deliklerin boyu en az 20 $\mathrm{m}$ seçilmeli, arının her $15 \mathrm{~m}$ ilerletilmesinden sonra sondajlar tekrarlanmalıdır.

ii. Koruyucu damar kazısının yapılması: Üretime başlamadan önce ani püskürmesine eğilimli damarın altında veya üstünde olaya eğilimli olmayan damarlarda (varsa) kazı çalışmalarına başlanır. Bu sırada ortamdaki gazın bir kısmı drene edilmiş olur.

iii. Kazı hızının ayarlanması: Yüksek kazı hızlarında püskürme olasılığı artmaktadır. Kazı hızı koruyucu bariyerin (yüksek basınç bölgesi ve arın arasındaki kısım) duraylılığını zayıflatmayacak şekilde ayarlanmalıdır.

iv. Tahrik ateşlemeleri: Koruyucu bariyer, patlayıcı madde kullanılarak aniden ortadan kaldırılabilir. Kontrollü bir şekilde gazın püskürtülmesi sağlanır.

\subsection{Ocak yangınları ile mücadele}

Maden işlemelerinde yangın önleme ve acil eylem planı bulunmalıdır. Bu planlar yangının önlenmesi, ihbarı ve kontrol altına alınması gibi iş paketlerinden oluşmalıdır. Aşağıda bu iş paketleri detaylandırılmaktadır.

i. Yangının önlenmesi: Yangın oluşturması muhtemel kaynaklar (üzerinde akım olan aletler, araçlar, kaynak veya asetilen kesme işlemleri, bant konveyör sistemleri gibi sürtünme ısısına yol açan faaliyetler, kendiliğinden yanmalar vb.) üzerinde gerekli tedbirler alınmalıdır.

ii. Yangının ihbarı: Yangını başlangıç aşamasında hızla bildirmeyi sağlayan sistemler kullanılmalıdır. Bu amaçla, yangının ortaya çıkma olasılığı yüksek olan konveyörlerin kritik noktalarına (bant girişleri, transfer noktaları ve konveyör bant boyunca bazı noktalar), başında görevli bulunmayan elektrikli makinelere, hava dönüș yolundaki stratejik yerlere monitörler konulmalıdır. Bu monitörler ilgili bölgeye ve ana izleme merkezine otomatik ihbar ve alarm sağlayacak şekilde tasarımlandırılmalıdır.

iii. Yangınla mücadele ekipmanı: Yangına müdahale kurtarma ekipleri tarafindan belirli bir plan program dahilinde yapılmalıdır. Madenlerde, yangınla mücadele ekipmanı ve malzemeleri (su boruları, yağmurlama sistemleri, su vanaları, su tankları, yangın hortumları, yangın söndürücüler, kuru toz kimyasal sistemi, köpük üretici sistemler, otomatik yangın söndürme sistemi, bölgesel olarak ve kömür arınında yangınla mücadele ekipmanı ve malzemeleri vd.) uygun yerlerde ve kapasitelerde bulundurulmalıdır [28]. Ahşap, kömür, plastik, kumaş vb. maddelerden kaynaklanan yangınlar su- $\mathrm{CO}_{2}$ yangın söndürücü ve genleșen köpük ile söndürülebilir. Mazot, fueloil, benzin vb. maddeler için ise $\mathrm{CO}_{2}$ yangın söndürücü, kuru kimyasal yangın söndürücü ve genleşen köpük kullanılabilir. Ek olarak, elektrik ekipmanlarındaki yangınlar $\mathrm{CO}_{2}$ yangın söndürücüleri ve kuru kimyasal yangın söndürücüler ile söndürülebilir. Magnezyum, titanyum vb. metal yangınları için is kum kullanılmaktadır.

Kömür madenlerinde, oksidasyon sonucunda meydana gelen kızıșma olaylarının mümkün olduğunca erken belirlenmesiyle ortaya çıkabilecek zararlar minimum düzeyde tutulabilecektir $[68,69]$. Sıcaklık, gazların yayılımı, havadaki nem miktarı ve oksijen oranındaki değişimler takip edilerek kendiliğinden yanma erken dönemde tespit edilebilir [70]. Alınan önlemlere rağmen kendiliğinden yanma 
başlamış ise yanma kaynağının hava ile teması kesilmesidir [27,59]. Kendiliğinden yanan kömürün hava ile temasinın kesilmesinde uygulanan yöntemler aşağıdaki gibi özetlenebilir.

i. Yanan kesimin kazılarak uzaklaştırılması: Yanma merkezi tespit edilir ve ulaşılabilir bir bölgede ise yanan kömür kazılır. Kazı işlemi sonucu hava ile temasa açık hale gelen yeni kömür yüzeyleri sızdırmaz bir şekilde sıvanır. Yanan kömür ise su/köpük ile soğutulur ve üzeri taş tozu/lateks ile kaplanarak en kısa yoldan ocak dışına çıkarılır.

ii. Yanan kesimin izole edilmesi: Kendiliğinden yanan kömürün hava ile etkileşimi kesilerek yanma olayı durdurulabilir.

iii. Inert gazların kullanılması: Ocak yangınları inert bir gaz kullanılarak söndürülebilir. Azot, karbondioksit veya yanma gazlarından biri yanma ortamına enjekte edilir. Böylece, yangın sahasındaki oksijen oranı düşürülerek yanmanın önüne geçilir.

\subsection{Termal konforun sağlanması}

Termal konforun sağlanabilmesi adına alınabilecek önlemler aşağıdaki gibidir.

i. Etkin bir havalandırma planıyla sıcaklığın kontrol edilmesi gerekir. İhtiyaca göre ocak havası ısıtılabilir ya da soğutulabilir.

ii. Ocak havasının sıcaklığını arttıracak faaliyetler (kömürün kendiliğinden yanması vd.) izlenerek kontrol altına alınabilir.

iii. Soğuğa karşı uygun giysiler kullandırılmalıdır. Baretlerin içi kulakları, alnı ve hatta gerekirse ağzı da kapatabilecek türde olmalıdır. İş eldivenleri soğuğa karşı yalıtımlı olmalıdır. Sıcaklığa karşı çalışanlar hafif, bol ve sıkı dokunmuş kumaşlardan yapılan giysiler giymelidir. Hava delikleri olan baretler takılmalıdır. Uygun sıklıkta sıvı alınmalıdır. Ayaklar, eller, yüz ve ense soğuk suyla islatılmalı/silinmelidir [30,59].

\subsection{Tozla mücadele}

Solunabilir toz konsantrasyonunun sağlı̆̆a zararlı olarak bilinen limitlerin altında tutulmasıyla tozun sebep olabileceği hastalıklar önlenebilir. Yeraltı madenlerinde, solunabilir toz kontrol planı yapılmalı, toza maruziyeti en aza indirecek çalışma yöntemleri tespit edilmeli ve uygun koruyucular temin edilmelidir [34]. Ocak tozlarını bastırmak için etkin bir havalandırmanın yanı sıra su/sıvı püskürtücüler ve toz toplama/filtreleme gereçleri kullanılmalıdır. Kömür arınlarına, yollara, bant konveyörlerin giriş ve dönüşlerine özellikle dikkat edilerek ocaktaki kömür döküntüleri ve kömür tozları için temizleme programları oluşturulmalıdır. Ayrıca, konveyörlerde sürtünme sonucuyla meydana gelen isı kömür tozunu tutuşturabilir. $\mathrm{Bu}$ sebepten bu alanlarda toz birikiminin önüne geçilmelidir. Diğer potansiyel tutuşturma kaynakları (akım olan aletler/devreler vd.) kömür tozu birikimi yönünden denetlenmelidir. Tozlar maden dışına çıkarılmalı veya başka bir yöntemle zararsız hale getirilmelidir. Kömür tozunu inert hale getirmek için kaya tozu ve başka yanmaz malzemeler kullanılmalıdır. Kömür damarına yakın olarak ocağın tabanı, yanları ve tavanı yüzeylerine kaya tozu uygulanabilir. Toz sıkılaştırma malzemeleri kullanılarak kaya tozunun koruyucu etkisine katkıda bulunulabilir [28,36].

\subsection{Tasmanla mücadele}

Yeryüzündeki tesisleri-yapılarını ve yeraltı tesislerini tasman etkisinden korunmak amaciyla topuklu/dolgulu yöntemlerle cevher üretimi gerçekleştirilebilir. $\mathrm{Bu}$ aşamada, topuk rezervinin/dolgu malzemesi miktarının belirlenmesi ekonomik bir analiz açısından gereklidir. Tasmandan hasar görecek yapıların maliyeti ile topuk olarak bırakılacak rezervin/dolgunun maliyeti karşılaştırılarak uygun bir üretim planlaması yapılmalıdır. Topuktaki rezervin ilerleyen dönemlerde tasman kontrollü işletme yöntemleri ile üretilmesi mümkün olabilmektedir $[45,46]$.

\subsection{Göçükle mücadele}

Göçük, başlıca iş sağlığı ve güvenliği eğitimlerinin yetersizliği, uygun tahkimat malzemelerinin seçilmemesi ve tahkimat yetersizliği/eksikliği, iyi yapılmayan iş organizasyonu, konsantre eksikliği gibi sorunlardan ötürü meydana gelmektedir. Bu hususlarda yapılacak iyileştirmelerle göçük oluşumunun önüne geçilebilir [52].

\subsection{Yeraltı suyu ile mücadele}

Yeraltı sularıyla mücadelede suyun çalışma bölgesine gelmesinin engellenmesi ve çalışma ortamdan uzaklaștırılması gibi seçenekler bulunmaktadır. Suyun çalışma bölgesine ulaşmasının engellenmesinde aşağıdaki seçenekler değerlendirilebilir [48].

i. Topuk bırakmak: Su içeren tabaka ile çalışmaların yürütüldüğü bölge arasında topuk bırakılarak suyun çalışma bölgelerine ulaşması engellenebilir.

ii. Dolgulu üretim uygulama: Su içeriği yüksek tavan taşı tabakalarının suyu içerisinde tutma durumunun bozulmaması adına göçertmeli yöntemler yerine dolgulu yöntemler uygulanabilir.

iii. Sondajlarla su drenajı: Su mevcudiyeti yüksek olan ve çalışmalar esnasında sorun yaratacağı düşünülen bölgelerin sondajlarla su drenajı sağlanabilir.

iv. Su barajlarının yapılması: Çok su gelirine yol açan eski çalışma bölgeleri ile aktif olarak çalışmaları yürütüldüğü bölgeleri birbirinden ayırmak için barajlar kullanılabilir. Ortam şartlarına bağlı 
olarak çeşitli tipte barajlar (kil barajlar, ağaç barajlar, beton barajlar ve su kapıları) uygulanmaktadır.

Çalışma ortamdan uzaklaştırılmasında ise su maden içinde oluşturulan havuzlarda biriktirilmekte ve buradan pompalar aracılı̆̆ıyla ocak dişına gönderilmektedir. Havuzlar suyun toplanmasını ve süzülmesini sağlarlar [50,51]. Açığa çıkan su miktarının düzenli ve az olması durumunda, kuyu derinleştirerek oluşturulan bölge havuz olarak kullanılabilir. Su debisinin düzensiz ve fazla olması durumunda ise madenin çeşitli noktalarında (kuyuya yakın bölgeler) havuzlar inşa edilir. Havuzların büyüklükleri ve sayısı su miktarına, su kaynaklarının maden içerisindeki dağılımlarına ve kullanılacak pompaların kapasitelerine bağlı olarak farklılık arz eder. Havuzlar mümkün olduğunca az geçirgen ve dayanıklı olan formasyonlar içerisinde oluşturulmalıdır. Havuzlardaki su pompalar yardımıyla ocak dışına gönderilir. Madencilikte en fazla kullanılan pompa türü santrifüj pompalardır [48].

\subsection{Diğer}

Gürültünün kaynağında azaltılabilmesi için önlemler alınmalıdır. Ortamdaki gürültü seviyesinin limitlerinin üzerinde olması durumunda çalışanların kișisel koruyucu donanımlar ile desteklenmesi gerekmektedir. Çalışanların şok emme özellikli uygun iş ayakkabıları ve elastik eldivenler kullanılması sağlanmalıdır.

\section{Sonuçlar ve Öneriler}

Çalışma kapsamında elde edilen sonuçları, aşağıdaki gibi özetlemek mümkündür.

i. Yeraltı ocak havasindaki gazların konsantrasyonları, bir ana izleme merkezinden takip edilmelidir. Herhangi bir uyarı durumunda tehlikenin kontrol altına alınabilmesi adına izleme merkezi tarafından gerekli önlemler alınmalıdır. Etkin bir havalandırma planı uygulanarak gazların seyreltilmesi ve izin verilebilir seviyelere çekilmesi sağlanmalıdır. Suda çözülebilir gazların açığa çıktığı patlatmalarda gazların kontrolünde su kullanılmalıdır. Kömür madenlerinde, metan patlamasının önlenmesi için metan gazının birikmesi önlenmeli, birikmişse alev alması engellenmelidir. Rahatlatma sondajlarının açılması, koruyucu kazı yapılması, üretim hızının kontrolü ve tahrik ateşlemeleri uygulamalarından biri veya birkaçıyla da metan ve kömür püskürmelerinin önüne geçilmelidir.

ii. Yangının oluşumu önlenmeli, önlenememesi durumlarda ise planlı bir şekilde kontrol altına alınmalıdır. Kömür madenlerinde, oksidasyon sonucunda meydana gelen kızışma olayların mümkün olduğunca erken tespit edilmelidir. Bunun mümkün olmadığı durumlarda yanan kömürün uzaklaştırılması/izole edilmesi ve inert gazların yanan bölgeye enjeksiyonu gibi seçenekler değerlendirilmelidir.

iii. Termal konforun sağlanabilmesi için etkin bir havalandırma planı uygulanmalıdır. Ocak havasının sıcaklığını ayarlamak için çeşitli teknolojiler kullanılabilir. Ocak havasının sıcaklığını, çalışma performansını etkileyecek şekilde değiștirebilecek faaliyetler izlenerek kontrol altına alınmalıdır. Kișisel önlemler ( sıvı alımı, uygun giyişiler vb.) ise kesinlikle ihmal edilmemelidir.

iv. Solunabilir toza maruziyeti en aza indirmek için uygun çalışma yöntemleri uygulanmalı (etkin bir havalandırma, su/su püskürtücüler, toz toplama/filtreleme gereçlerinin kullanımı, toz temizleme) ve kişisel koruyucular kullanılmalıdır. Kömür madenlerinde ise yollarda ve sürtünme kaynaklı ısı açı̆̆a çıkarması muhtemel alanlarda toz birikmesi engellenmelidir. Ayrıca, kömür tozunu inert hale getirmek için çeşitli yanmaz malzemeler kullanılmalıdır.

v. Tasman etkisinden maden çevresini korumak için topuklu veya dolgulu üretim yöntemleri tercih edilmelidir.

vi. Göçükle mücadele amacıyla çalışanlara kapsamlı eğitimler verilmeli, uygun tahkimat bileşenleri kullanılmalı ve iyi bir iş organizasyonu yapılmalıdır.

vii. Yeraltı sularıyla mücadelede çalışma bölgesine suyun gelmesinin engellenmeli ve çalışma ortamındaki su uzaklaştırılmalıdır. Suyun çalışma bölgesine ulaşmasının engellenmesinde topuk bırakılması, dolgulu üretim uygulanması, sondajlarla su drenajı yapılması ve su barajlarının yapılması gibi seçenekler değerlendirilmelidir. Çalışma ortamındaki su ise havuzlarda biriktirilerek pompalar yardımıyla ocak dışına gönderilmelidir.

viii. Gürültü ve titreșimin kontrolünde ise bu faktörlerin şiddetlerinin azaltılmasına yönelik önlemler alınmalıdır. Ortamdaki gürültü/titreşim seviyesinin limitlerinin üzerinde olması halinde çalışanlar kişisel koruyucularla desteklenmelidir.

Maden kazaları sonucunda yaralanmalar ve telafisi mümkün olmayan can kayıpları yaşanabilmektedir. Ayrıca, maden işletmeleri de ekonomik olarak zarara uğramaktadır. Yeraltı maden işletmelerinde, yukarıda belirtilen konulara yönelik gerekli tedbirler alınmalı ve bu durumların gerçekleşmesinin önlenmesiyle/etkilerinin azaltılmasıyla sağlanacak avantajlar (üretim kaybının, üretim programının aksamasının, üretim ekipmanlarının tahribinin önlenmesi vb.) göz önünde bulundurulmalıdır. $\mathrm{Bu}$ kapsamda bilinç oluşturulmalı ve denetleme faaliyetleri etkin bir şekilde yürütülmelidir. 


\section{Kaynakça}

[1] Önal G. 2019. Ülke Kalkınmasında Madenciliğin Önemi.

http://www.cinermediagroup.com/documents/ 153645324347b30ec56284f.doc(Erișim Tarihi: 10.06.2020).

[2] Mallı, T., Kun, M., Köse, H. 2014. Yeraltı Kömür İşletmelerinde Gaz İzleme ve Erken Uyarı Sistem Teknolojisinin İș Kazalarının Önlenmesindeki Önemi. DEÜ Mühendislik Fakültesi Mühendislik Bilimleri Dergisi, 46(1), 59-67.

[3] ES. 2016. Maden İşletmelerinde Risk Faktörleri. Risk Değerlendirme Bülteni. Ekol Sigorta, Sayı: 2016/05.

[4] Köse, H., Tatar, Ç. 2011. Madenlerde Yeraltı Üretim Yöntemleri. Dokuz Eylül Üniversitesi Mühendislik Fakültesi Yayınları, 246 sayfa.

[5] Akkaya, C. 2001. Maden Sektöründe Risk Faktörleri. Türk Tabipleri Birliği Mesleki Sağlık ve Güvenlik Dergisi, 5, 38-41.

[6] Semin, M.A., Levin, L.Y. 2019. Stability of Air Flows in Mine Ventilation Networks. Process Safety and Environmental Protection, 124, 167171.

[7] Keith, W., Brian, P., Daniel, S.J. 2015. The Practice of Mine Ventilation Engineering. International Journal of Mining Science and Technology, 25(2), 165-169.

[8] Wang, G., Li, W., Wang, P., Yang, X., Zhang, S. 2017. Deformation and Gas Flow Characteristics of Coal-like Materials under Triaxial Stress Conditions. International Journal of Rock Mechanics and Mining Sciences, 91, 72-80.

[9] Durşen, M., Yasun, B. 2012. Yeraltı Madenlerinde Bulunan Zararlı Gazlar ve Metan Drenajı. İSGÜM, Ankara.

[10] Hartman, H., Mutmansky, J.M., Ramanı, R.V., Wang, Y.J. 1997. Mine Ventilation and Air Conditioning. 3. Baskı, John Wiley \& Sons, New York, 752 sayfa.

[11] Ayvazoğlu, E., Ökten, G., Tuncel, Z. 1994. Yeraltı Kazılarında Havalandırma Uygulamaları. Ulaşımda Yeraltı Kazıları 1.Sempozyumu, 1-3 Aralık, İstanbul, 283-307.

[12] Aydin, G. 2014. The Modeling of Coal-related CO2 Emissions and Projections into Future Planning. Energy Sources Part A: Recovery, Utilization, and Environmental Effects, 36(2), 191-201.

[13] Euler, D. 2017. Application of Ventilation Management Programs for Improved Mine Safety. International Journal of Mining Science and Technology, 27(4),647-650.
[14] Jie, C., Wenpu, L. 2017. Numerical Simulation of Gas Migration into Mining-induced Fracture Network in the Goaf. International Journal of Mining Science and Technology, 27(4), 681-685.

[15] Karakurt, I., Aydin, G., Aydiner, K. 2011. Mine Ventilation Air Methane as A Sustainable Energy Source. Renewable and Sustainable Energy Reviews, 15, 1042-1049.

[16] Karakurt, I., Aydin, G., Aydiner, K. 2012. Sources and Mitigation of Methane Emissions by Sectors: A Critical Review. Renewable Energy, 39(1), 40-48.

[17] Düzgün, H.S., Leveson, N. 2018. Analysis of Soma Mine Disaster using Causal Analysis based on Systems Theory (CAST). Safety Science, 110, 3757.

[18] Ding, Y., Yue, X.Q. 2018. An Experimental Investigation of the Roles of Water Content and Gas Decompression Rate for Outburst in Coal Briquettes. Fuel, 234, 1221-1228.

[19] Esen, O., Ökten, G., Fişne, A., 2017. Türkiye'de Meydana Gelen Ani Gaz ve Kömür Püskürmesi Olaylarının Değerlendirilmesi ve Olaylarla Mücadelede Alınacak Önlemler. Madencilik, 56(3), 99-108.

[20] Wang, S., Elsworth, D., Liu, J. 2015. Rapid Decompression and Desorption Induced Energetic Failure in Coal. Journal of Rock Mechanics and Geotechnical Engineering, 7(3), 345-350.

[21] Hansen, R. 2019. Fire Behaviour of Multiple Fires in a Mine Drift with Longitudinal Ventilation. International Journal of Mining Science and Technology, 29(2), 245-254.

[22] Singh, A.K., Singh, R.V.K., Singh, M.P., Chandra, H., Shukla N.K. 2007. Mine Fire Gas Indices and their Application to Indian Underground Coal Mine Fires. International Journal of Coal Geology, 69(3), 192-204.

[23] Melody, S.M., Johnston, F.H. 2015. Coal Mine Fires and Human Health: What Do We Know? International Journal of Coal Geology, 152, 1-14.

[24] Lia, C., Hub, L., Lic, Z., Caod, Z. 2012. A Fume Concentration Model of Underground Mine Fire and Its Calculation. Energy Procedia, 16, 320326.

[25] Oliveira, M.L.S., Bernardo, D.P., Kátiada, F.T., Saikia, B.B.K., Silva, L.F.O. 2019. Pollution from Uncontrolled Coal Fires: Continuous Gaseous Emissions and Nanoparticles from Coal Mines. Journal of Cleaner Production, 215, 1140-1148.

[26] Eroğlu, N., Gouws, M.J. 1993. Kömürün Kendiliğinden Yanmasına Ait Kuramlar. Madencilik, 32(2), 13-18. 
[27] Didari, V. 1986a. Yeraltı Ocaklarında Kömürün Kendiliğinden Yanması ve Risk İndeksleri. Madencilik, 15(4), 29-34.

[28] Sabır, H.U. 2011. Yeraltı Kömür Madenlerinde Güvenlik ve Sağlık. ILO Uygulama Kılavuzu, Ankara, Uluslararası Çalışma Ofisi.

[29] Anderson, R., De Souza, E. 2017. Heat Stress Management in Underground Mines. International Journal of Mining Science and Technology, 27 (4), 651-655.

[30] Arıtan, E., Tümer, M., Şensöğüt, C. 2017. Yeraltı Kömür Ocaklarında Termal Konfor Şartlarının İncelenmesi. Uluslararası Maden İşletmelerinde İşçi Sağlı̆̆ı ve İş Güvenliği Sempozyumu'2017, 2-3 Kasım, Adana, 521-533.

[31] Roghanchi, P., Kocsis, K.C. 2018. Challenges in Selecting An Appropriate Heat Stress Index to Protect Workers in Hot and Humid Underground Mines. Safety and Health at Work, 9(1), 10-16.

[32] Önder, M., Saraç, S. 2003. Yeraltı Ocaklarındaki İklimsel Koşulların Önceden Belirlenmesi. DEÜ Mühendislik Fakültesi Fen ve Mühendislik Dergisi, 5, 137-146.

[33] Sasmito, A.P., Kurnia, J.C., Birgersson E., Mujumdar A.S. 2015. Computational Evaluation of Thermal Management Strategies in An Underground Mine. Applied Thermal Engineering, 90, 1144-1150.

[34] Li, S., Xie, B., Hu, S., Jin, H., Liu, H, Tan, X., Zhou, F. 2019. Removal of Dust Produced in the Roadway of Coal Mine using A Mining Dust Filtration System. Advanced Powder Technology, 30(5), 911-919.

[35] Ren, W., Shi, J., Guo, Q., Zhao, Q., Bai, L. 2017. The Influence of Dust Particles on the Stability of Foam used as Dust Control in Underground Coal Mines. Process Safety and Environmental Protection, 111, 740-746.

[36] Wang, P., Tan, X., Cheng, W., Guo, G., Liu, R. 2018. Dust Removal Efficiency of High Pressure Atomization in Underground Coal Mine. International Journal of Mining Science and Technology, 28(4), 685-690.

[37] Wanxing, R., Deming, W., Qing, G., Bingzhao, Z. 2014. Application of Foam Technology for Dust Control in Underground Coal Mine. International Journal of Mining Science and Technology, 24(1), 13-16.

[38] İmancı, C. 2014. Döküm Atölyelerinde Termal Konfor Şartlarının Incelenmesi. İş Sağlığı ve Güvenliği Uzmanlık Tezi/Araştırma, T.C. Çalışma ve Sosyal Güvenlik Bakanlığı İş Sağlığı ve Güvenliği Genel Müdürlügü.
[39] Aydin, G., Karakurt, I., Aydiner, K. 2012. Analysis and Mitigation Opportunities of Methane Emissions from Energy Sector. Energy Sources Part A: Recovery, Utilization, and Environmental Effects, 34(11), 967-982.

[40] Lebecki, K., Małachowski, M., Sołtysiak, T. 2016. Continuous Dust Monitoring in Headings in Underground Coal Mines. Journal of Sustainable Mining, 15(4), 125-132.

[41] RG. 2013. Tozla Mücadele Yönetmeliği. T.C. Aile, Çalıșma ve Sosyal Hizmetler Bakanlığı, İș Sağlığı ve Güvenliği Genel Müdürlüğü, 05.11.2013 tarihli ve 28812 sayılı Resmi Gazete.

[42] Tripathy, D.P., Ala, C.K. 2018. Identification of Safety Hazards in Indian Underground Coal Mines. Journal of Sustainable Mining, 17(4), 175-183.

[43] Didari, V. 1986b. Kömür Tozu Patlaması. Madencilik, 14(4), 23-29.

[44] Shan, F.S., Jiang, C., Bo, Y., Shu, D.Z. 2009. Re-use Strategy of Subsided Land based on Urban Space Ecological Compensation: Case Study for Xuzhou Mining Area for Example. Procedia Earth and Planetary Science, 1(1), 982-988.

[45] Wang, J., Zhang, J., Feng, Y. 2019. Characterizing the Spatial Variability of Soil Particle Size Distribution in an Underground Coal Mining Area: An Approach Combining Multi-Fractal Theory and Geostatistics. CATENA, 176, 94-103.

[46] Akçın, H., Aratoğlu, T., Şahin, H. 2003. Madencilikte Tasman Hasarlarından Korunmaya Yönelik 3B Topuk Planması. 1. Ulusal Mühendislik Ölçmeleri Sempozyumu, 3031 Ekim, İstanbul, 466-478.

[47] Jing, Z., Wang, J., Zhu, Y., Feng, Y. 2018. Effects of Land Subsidence resulted from Coal Mining on Soil Nutrient Distributions in a Loess Area of China. Journal of Cleaner Production, 177, 350361.

[48] Tatar, C.., Köse, H., Gürgen, S. 2013. Madenlerde Su Atımı ve Pompalar. Dokuz Eylül Üniversitesi Mühendislik Fakültesi Yayınları, 125 sayfa.

[49] Greenslide, W.M. 1976. Yeraltı Madenciliğinde Suatım Sorunları. Madencilik, 15(3), 44-47.

[50] Alvarez, R., Ordóñez, A., Loredo, R.G.J. 2018 . An Estimation of Water Resources in Flooded, Connected Underground Mines. Engineering Geology, 232, 114-122.

[51] Chi, M., Zhang, D., Fan, G., Zhang, W., Liu, H. 2019. Prediction of Water Resource Carrying Capacity by the Analytic Hierarchy Processfuzzy Discrimination Method in a Mining Area. Ecological Indicators, 96(1), 647-655.

[52] Ateş, C.D. 2017. Bir Yeraltı Taş Kömürü Madeninde Göçük ve Taş-kavlak Düşmelerinden 
Kaynaklanan Kazaların Kök Nedenlerinin Bulunması.

http://iohsc2017.org/upload/20594e5d.pdf (Erişim Tarihi: 20.05.2020).

[53] Aydin, G., Karakurt, I., Aydiner, K. 2013a. Wear Performance of Sawblades in Processing of Granitic Rocks and Development of Models for Wear Estimation. Rock Mechanics and Rock Engineering, 46(6), 1559-1575.

[54] Roy, M.P., Singh, P.K., Sarim, M., Shekhawat, L.S. 2016. Blast Design and Vibration Control at an Underground Metal Mine for the Safety of Surface Structures. International Journal of Rock Mechanics and Mining Sciences, 83, 107115.

[55] Aydin, G., Karakurt, I., Aydiner, K. 2013b. Investigation of the Surface Roughness of Rocks Sawn by Diamond Sawblades. International Journal of Rock Mechanics and Mining Sciences, 61, 171-182.

[56] Marilena, C., Mauricio, D., Jacopo, S. 2012. Complexity Analysis of Blast-induced Vibrations in Underground Mining: A Case Study. International Journal of Mining Science and Technology, 22(1), 125-131.

[57] Lechner, A.M, Kassulke, O., Unger, C. 2016. Spatial Assessment of Open Cut Coal Mining Progressive Rehabilitation to Support the Monitoring of Rehabilitation Liabilities. Resources Policy, 50, 234-243.

[58] Karakurt, I., Aydin, G., Aydiner, K. 2013. Predictive Modelling of Noise Level Generated during Sawing of Rocks by Circular Diamond Sawblades. Sadhana-Academy Proceedings in Engineering Science, 38(3), 491-511.

[59] Thakur, P. 2019. Advanced Mine Ventilation: Respirable Coal Dust, Combustible Gas and Mine Fire Control. Woodhead Publishing, $528 \mathrm{~s}$.

[60] Aydın, Y., Barış, K., 2015. Yeratı Kömür Ocaklarında Gaz İzleme Ağları Sensör Ölçümlerinin ve Konumlarının Doğruluğunun Analizi: TTK Kozlu Müessesesi. Madencilik, 54(2), 19-32.

[61] Zhang, Y., Yang, C., Li, Y., Huang, Y., Zhang, J., Zhang Y., Li Q. 2019. Ultrasonic Extraction and Oxidation Characteristics of Functional Groups during Coal Spontaneous Combustion. Fuel, 242, 287-294.

[62] Bochorishvili, N., Chikhradze, N., Mataradze, E., Akhvlediani, I., Chikhradze, M. 2015. New Suppression System of Methane Explosion in Coal Mines. Procedia Earth and Planetary Science, 15, 720-724.

[63] Shi, L., Wang, J., Zhang, G., Cheng, X., Zhao, X. 2017. A Risk Assessment Method to Quantitatively Investigate the Methane
Explosion in Underground Coal Mine. Process Safety and Environmental Protection, 107, 317 333.

[64] Kundu, S., Zanganeh, J., Moghtaderi, B. 2016. A Review on Understanding Explosions from Methane-air Mixture. Journal of Loss Prevention in the Process Industries, 40, 507523.

[65] Kursunoglu, N., Onder, M. 2019. Application of Structural Equation Modeling to Evaluate Coal and Gas Outbursts. Tunnelling and Underground Space Technology, 88, 63-72.

[66] Xu, L., Jiang, C. 2017. Initial Desorption Characterization of Methane and Carbon Dioxide in Coal and Its Influence on Coal and Gas Outburst Risk. Fuel, 203, 700-706.

[67] Yalçın, E. 2012. Yeraltı Havalandırması. Dokuz Eylül Üniversitesİ Mühendislik Fakültesi Yayınları, 399 sayfa.

[68] Onifade, M., Genc, B. 2018. Spontaneous Combustion of Coals and Coal-shales. International Journal of Mining Science and Technology, 28(6), 933-940.

[69] Xi, Z., Wang, X., Wang, X., Wang, L., Li, D., Guo, X., Jin, L. 2019. Polymorphic Foam Clay for Inhibiting the Spontaneous Combustion of Coal. Process Safety and Environmental Protection, 122, 263-270.

[70] Zhang, Q., Ma, Q.J. 2015. Dynamic Pressure Induced by A Methane-air Explosion in A Coal Mine. Process Safety and Environmental Protection, 93, 233-239. 